HEAD AND NECK

\title{
Results of a survey on elderly head and neck cancer patients on behalf of the Italian Association of Radiotherapy and Clinical Oncology (AIRO)
}

\author{
Risultati di una survey su pazienti anziani con tumore testa collo - a nome \\ dell'Associazione Italiana di Radioterapia e Oncologia Clinica (AIRO)
}

\begin{abstract}
Liliana Belgioia ${ }^{1}, 2$, Francesca De Felice ${ }^{3}$, Almalina Bacigalupo², Daniela Alterio ${ }^{4}$, Angela Argenone ${ }^{5}$, Elisa D’Angelo ${ }^{6}$, Isacco Desideri ${ }^{7}$, Pier Francesco Franco ${ }^{8}$, Anna Merlotti ${ }^{9}$, Daniela Musio ${ }^{3}$, Ester Orlandi ${ }^{10}$, Stefano Ursino ${ }^{11}$, Fabiola Paiar ${ }^{11}$

${ }^{1}$ Health Science Department (DISSAL), University of Genoa, Italy; ${ }^{2}$ Radiation Oncology Department, Policlinico San Martino Hospital, Genoa, Italy; ${ }^{3}$ Department of Radiotherapy, Policlinico Umberto I, "Sapienza" University of Rome, Italy; ${ }^{4}$ Division of Radiation Oncology, IEO, European Institute of Oncology IRCCS, Milan, Italy; ${ }^{5}$ Radiation Oncology Unit, A.O.R.N. San Pio Benevento, Italy; ${ }^{6}$ Radiation Oncology Unit, University Hospital of Modena, Italy; ${ }^{7}$ Azienda Ospedaliera Universitaria Careggi, Radiotherapy Unit, Oncology Department, University of Florence, Italy; ${ }^{8}$ Department of Oncology, Radiation Oncology, School of Medicine, University of Turin, Italy; ${ }^{9}$ Department of Radiation Oncology, S. Croce and Carle Teaching Hospital, Cuneo, Italy; ${ }^{10}$ Radiotherapy 2 Unit, Fondazione IRCCS Istituto Nazionale dei Tumori, Milan, Italy; ${ }^{11}$ Department of Radiation Oncology, University Hospital of Pisa, Italy
\end{abstract}

\begin{abstract}
SUMMARY
Objective. Over the years, evidence-based data and technical improvements have consolidated the central role of radiation therapy (RT) in head and neck cancer (HNC) treatment, even in the elderly. This survey aimed to describe the management of the elderly HNC patients among Italian Radiation Oncology Departments (RODs) and provide possible suggestions for improvement. Methods. An online survey based on 43 questions was sent to RODs via email. For each RODs, a radiation oncologist with expertise in HNC was invited to answer questions addressing his/her demographic data, ROD multidisciplinary unit (MU) organisation and ROD management policy in elderly HNC patients.

Results. In total, 68 RODs answered, representing centres located in 16 Italian regions. MU was considered the core of $\mathrm{HNC}$ patient management in almost all the entire country. However, in many RODs, there was minimal access to a routinely comprehensive geriatric assessment at diagnosis. Most treatments were reported by respondents as curative ( $89 \%$ on average) and the preferred treatment technique was intensity modulated radiation therapy (IMRT). A considerable variation between RODs was found for RT target volumes. There was a relation between the specialist's years of experience and type of concomitant systemic therapy prescribed.

Conclusions. Substantial differences in elderly HNC management have been found, especially concerning patient clinical evaluation and target volume delineation. This survey shows the necessity to design a prospective national trial to provide a uniform treatment strategy and define an effective patient-centred approach.
\end{abstract}

KEY WORDS: elderly patients, head and neck cancer, radiotherapy, combined treatment

\section{RIASSUNTO}

Obiettivo. Il ruolo della radioterapia nel trattamento dei tumori testa collo è ormai consolidato anche per i pazienti anziani. Lo scopo di questa survey è quello di descrivere la gestione del paziente anziano con tumore testa collo tra i centri di radioterapia italiani e fornire possibili suggerimenti di miglioramento.

Metodi. Una survey online basata su 43 domande è stata inviata ai vari centri via mail. Per ciascun centro un radioterapista oncologo $(R O)$ esperto nel trattamento di questi tumori è stato invitato a rispondere a domande riguardanti i suoi dati demografici, l'organizzazione del team multidisciplinare (TM) del centro e la gestione del paziente anziano con tumore testa collo. Risultati. In totale hanno risposto $68 \mathrm{RO}$, rappresentanti centri situati in 16 regioni italiane. Il TM è stato considerato il nucleo della gestione dei pazienti con tumore testa collo in quasi tutto il paese. In molti centri c'era un accesso ridotto a una routinaria valutazione
Received: January 19, 2020

Accepted: August 29, 2020

Correspondence

Liliana Belgioia

Health Science Department (DISSAL), University of Genoa, via Pastore 1, 16132 Genova, Italy Tel. +39010 5558050

E-mail: liliana.belgioia@unige.it

Funding

None.

Conflict of interest

The Authors declare no conflict of interest.

How to cite this article: Belgioia L, De Felice F, Bacigalupo A, et al. Results of a survey on elderly head and neck cancer patients on behalf of the Italian Association of Radiotherapy and Clinical Oncology (AIRO). Acta Otorhinolaryngol Ital 2020;40:405-409. https://doi. org/10.14639/0392-100X-N0618

() Società Italiana di Otorinolaringoiatria e Chirurgia Cervico-Facciale

\section{Ф)(1)}

This is an open access article distributed in accordance with the CC-BY-NC-ND (Creative Commons Attribution-NonCommercial-NoDerivatives 4.0 International) license. The article can be used by giving appropriate credit and mentioning the license, but only for non-commercial purposes and only in the original version. For further information: https:// creativecommons.org/licenses/by-nc-nd/4.0/deed.en 
geriatrica multidimensionale. La maggior parte dei trattamenti (89\%) aveva intento curativo e la radioterapia a intensità modulata (IMRT) era la tecnica di trattamento di scelta. È stata rilevata una notevole variazione tra i vari centri circa la scelta dei volumi target e una correlazione tra gli anni di esperienza dello specialista e il tipo di terapia sistemica concomitante prescritta.

Conclusioni. Sono state riscontrate differenze sostanziali nella gestione del paziente anziano con tumore testa collo, in particolare per quanto riguarda la valutazione clinica del paziente e la delineazione del volume target. Questa survey mostra la necessità di progettare una sperimentazione nazionale prospettica per omogeneizzare la strategia di trattamento e definire un approccio efficace incentrato sul paziente.

PAROLE CHIAVE: pazienti anziani, tumore della testa collo, radioterapia, trattamenti combinati

\section{Introduction}

Head and neck cancer (HNC) is the sixth most frequent malignancy worldwide ${ }^{1}$. Despite an increase in the incidence of human papilloma virus (HPV)-related cancer in younger patients, HNC can still be considered pertinent to an elderly population ${ }^{1,2}$. Current data estimate that more than $60 \%$ of all new HNC diagnoses occur in patients aged over 65 years ${ }^{2}$. Whether a standard treatment approach, especially in locally advanced cases, is applicable to an elderly population represents a crucial issue. It has been reported that patient age affects the benefits of chemotherapy in this setting ${ }^{3,4}$. The update of the meta-analysis of chemotherapy in head and neck cancer (MACH-NC) showed that the benefit of concomitant chemotherapy was lower in older patients, and, similarly, there was a decreasing effect of bio-radiotherapy (RT) with age in a subgroup analysis of the Bonner's study ${ }^{3,4}$. Nevertheless, these studies were not sufficiently powered for this subgroup analysis and, generally, elderly patients were grossly underrepresented in clinical trials, accounting for $<5 \%$ of enrolled cases. The worse clinical outcomes observed in elderly patients are mainly due to patient-related factors, such as general conditions, cognitive status and comorbidity. Consequently, these patients are at a higher risk to develop toxicity leading to the delivery of suboptimal treatments ${ }^{5}$. In recent years, geriatric evaluation and categorisation have gained importance in order to define the most appropriate management. Several screening tools - geriatric 8 (G8), mini-cog, adult comorbidity evaluation-27 (ACE-27), Charlson comorbidity index (CCI), vulnerable elders survey (VES-13) - have been developed to stratify elderly patients into those who would tolerate standard therapy and those who would be at an increased risk of suffering severe toxicity ${ }^{5}$. However, definitive data on impact of these tools for selected frail patients in clinical practice are still scarce.

The purpose of the present national survey was to analyse the patterns of care across Italian Radiation Oncology Departments (RODs) to identify trends that may provide insights into the management of $\mathrm{HNC}$ among the elderly.

\section{Materials and methods}

An anonymous survey was conducted online using the free
Survey Monkey platform (www.SurveyMonkey.com). The survey was open from February to April 2018.

Italian RODs were invited to participate via e-mail with an introduction letter using the AIRO mailing list and to delegate survey compilation to a radiation oncologist with expertise in HNC. Each radiation oncologist was allowed to answer the survey only once. Data were referred to the HNC patient population treated during the year 2017 in each department.

\section{Survey description}

A panel of experts of the AIRO Head and Neck working group designed a 43 item-based self-produced questionnaire. The 43 items were defined over a multi-step process and subsequently validated by the AIRO Head and Neck working group. The items were grouped in four sections, including i) ROD and equipment general information, ii) multidisciplinary team characteristics, iii) management of elderly (defined as over 70 years) $\mathrm{HNC}$ patients treated with curative intent, iv) management of elderly HNC patients treated with palliative intent. Geriatric assessment (screening tools) and treatment data (total dose, dose per fraction, target volume, technique, regimens of concomitant systemic therapy) were collected.

Statistical analysis. All values - numbers, percentages and estimates - presented in the results are derived from survey data that are prone to sampling limitations. The values met the criteria for statistical reliability. Values that did not meet reliability criteria were suppressed. Descriptive analysis focused on percentages, since they take into account any changes in the size of the total cohort and facilitate the comparison of values across variables.

To identify relatively homogeneous groups based on selected characteristics such as years of experience in HNC field, number of HNC treatment per year in ROD, type of chemotherapy and RT treatment volumes, we used the k-means clustering method via principal components analysis using the Hartigan and Wong method ${ }^{6}$. Multidimensional data are represented on two axes and the cluster centroids (vector of mean values of each variable) can be defined. Statistical analysis was carried out using R-Studio 0.98.1091 software. 


\section{Results}

\section{Centre distribution}

The survey was sent to all Italian RODs $(\mathrm{n}=195)$ and 68 answers were received (response rate $=34.8 \%$ ). Globally, RODs were recorded in 16 regions, distributed as 32 public structures (48\%), 19 University departments (28\%), 16 private centres providing health care through the national healthcare system $(23 \%)$ and 1 private centre. The highest number of RODs was located in the northern regions $(n=40)$, followed by central $(n=19)$ and southern regions $(n=9)$.

\section{Participant characteristics}

For each ROD, a radiation oncologist answered the survey. In total, 46 radiation oncologists were aged 30-50 (67.6\%) and $22(32.4 \%)$ were over 50 years old. None was less than 30 years old. Thirty-nine were females $(57.4 \%)$ and 29 were male $(42.6 \%)$. Forty-seven $(69.2 \%)$ had been working as a specialist for more than 10 years. All responders declared daily clinical practice in $\mathrm{HNC}$ field and the vast majority $(n=64 ; 94.1 \%)$ believed that selected fit elderly patients could receive standard treatment.

\section{HNC patient population characteristics}

The global number of HNC patients treated per year per RODs varied from fewer than $10(\mathrm{n}=2 ; 2.9 \%)$ to more than $100(\mathrm{n}=7 ; 10.3 \%)$; about half of RODs $(\mathrm{n}=31 ; 45.6 \%)$ ranged between 10 to $50 \mathrm{HNC}$ patients. In 2017, the average number of RT treatment courses in elderly HNC patients was 22 , with a large variation from fewer than 5 treatments per year in 5 RODs to $\geq 50$ in 4 RODs.

\section{Multidisciplinary unit characteristic}

In total, 58 RODs discussed HNC cases in a multidisciplinary unit (MU) and most $(\mathrm{n}=46 ; 79.3 \%)$ at regular weekly intervals. Other than maxillofacial/head and neck surgeon, medical oncologist, radiation oncologist, radiologist and histopathologist, the other main highly specialised figures included in the MU were nutritionist ( $\mathrm{n}=28 ; 48.3 \%)$, pain specialist $(\mathrm{n}=20 ; 34.5 \%)$, speech and language therapist $(\mathrm{n}=12$; $20.7 \%)$ and head and neck dedicated nurse $(\mathrm{n}=24 ; 41.4 \%)$. Only 4 (6.9\%) MUs had a geriatrician within the team.

\section{Evaluation of the elderly patient}

In clinical practice, 36 RODs (52.9\%) used different index score, mainly including Charlson's comorbidity index, ACE27 score or G-8 tool, to actively screen elderly patients for disorders. Before treatment decision, 11 (16.2\%) RODs routinely performed evaluation of function and quality of life in elderly HNC patients, but only 7 (10.3\%) RODs systemati- cally applied the comprehensive geriatric assessment (CGA). In $14(20.6 \%)$ RODs, elderly patients scheduled to receive RT with or without concomitant chemotherapy were offered prophylactic percutaneous endoscopic gastrostomy (PEG) tube.

\section{Radiation therapy treatment}

In 2017, among the analysed centres, 1404 elderly HNC patients received RT with curative $(\mathrm{n}=1255)$ or palliative $(\mathrm{n}=149)$ intent. In the curative RT setting, 268 patients were treated with concurrent platinum-based chemoradiotherapy (CRT), 108 patients with RT plus cetuximab, 377 patients with definitive RT, 98 patients received induction chemotherapy before RT, 31 patients interstitial brachytherapy and 373 patients underwent surgery followed by adjuvant RT $(\mathrm{n}=318)$ or CRT $(\mathrm{n}=55)$. Adjuvant CRT was mainly programmed in case of adverse risk features, including positive margins and extranodal extension.

In case of curative RT, more than $85 \%$ of elderly patients were treated using intensity-modulated RT (IMRT) technique at a planned dose of 66-70 Gy delivered in conventional fractionation (2-2.2 Gy/fraction). Less than $10 \%$ of patients received accelerated RT. In total, 30/68 (44\%) RODs delineated standard treatment volumes, based on TNM stage and HNC sub-site and 38/68 (56\%) RODs proposed target volume reduction.

In the reduced volume group, $9 / 38$ (23.7\%) RODs delineated only the macroscopic disease sites and 29/38 (76.3\%) defined as target the macroscopic disease sites (including the possible nodal involvement) plus the first uninvolved lymphatic drainage echelon.

In case of concurrent treatment, RT with cetuximab was considered the first option in only 3 RODs; the remainder $(\mathrm{n}=65 ; 95.6 \%)$ proposed cetuximab only if patients were considered medically unfit for concomitant platinum-based chemotherapy.

During treatment, 28 RODs (48.3\%) declared a higher hospitalisation request than in the case of non-elderly patients.

\section{Cluster analysis}

Four variables - year of experience in HNC field, number of HNC treatment per year in ROD, type of chemotherapy and RT treatment volumes - were used in the clustering analysis. These variables were graphically depicted using two axes which represented $76.71 \%$ of the total variability (Fig. 1). Using these two components, we found three clusters of RTUs. Details are presented in Figure 1. Cluster 1 was defined by 13 RODs, including Abruzzi $(\mathrm{n}=1)$, Calabria $(\mathrm{n}=1)$, Latium $(\mathrm{n}=2)$, Liguria $(\mathrm{n}=1)$, Lombardy $(\mathrm{n}=3)$, Piedmont $(\mathrm{n}=1)$, Trentino Alto Adige $(\mathrm{n}=1)$, Tuscany $(\mathrm{n}=1)$ and Veneto $(\mathrm{n}=2)$. Cluster 2 was formed by $45 \mathrm{ROD}$ distributed as Abruzzi ( $n=2)$, Campania $(n=3)$, Emilia Ro- 


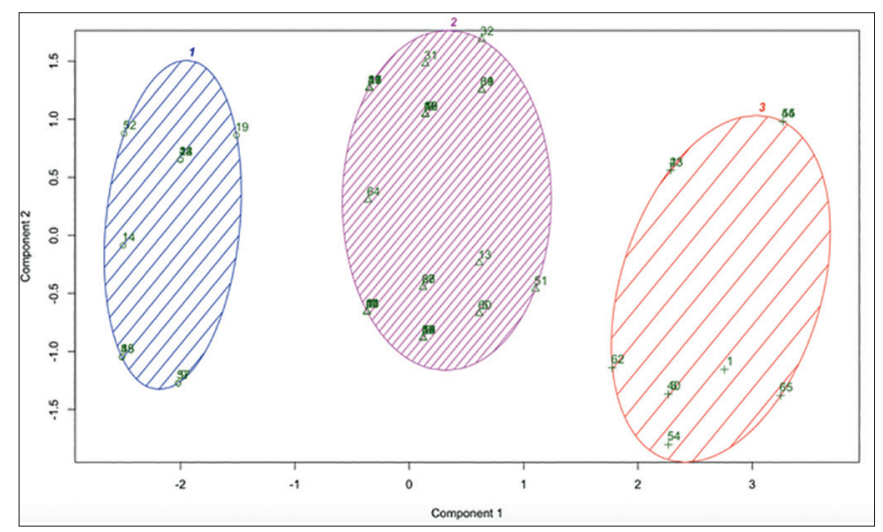

Figure 1. Cluster plot found through k-means clustering analysis.

magna $(n=3)$, Friuli Venezia Giulia $(n=1)$, Latium $(n=4)$, Liguria ( $n=3)$, Lombardy $(n=12)$, Marches $(n=1)$, Molise $(n=1)$, Piedmont $(n=5)$, Puglia $(n=2)$, Sardinia $(n=1)$, Tuscany $(n=5)$ and Veneto $(n=2)$. The remaining 10 RODs defined cluster 3 ( $n=1$ Emilia Romagna, Piedmont, Veneto, Campania; $n=2$ Puglia; $n=4$ Lombardy).

Cluster 1 showed high young (in term of year of experience) HNC specialists and the highest cetuximab use. Cluster 2 prescribed platinum-based CHT and presented the highest specialist experience. Cluster 3 showed centroid values for specialist experience and chemotherapy prescription.

\section{Discussion}

This survey firstly addresses at the national level the relevant issue of the RODs choices for the treatment of elderly patients with locally advanced HNC. In most RODs, a MU discussion is held for HNC cases. The majority of elderly patients (56\%) received RT with curative doses but with reduced volumes (in these cases, about $24 \%$ and $76 \%$ of RODs delineated only the macroscopic disease sites or macroscopic disease sites plus the first uninvolved lymphatic drainage echelon, respectively). The majority of patients received intensity modulated radiotherapy. Interestingly, cluster analysis showed that more experienced specialists prescribed cisplatin-based chemotherapy more often than young HNC specialists did. Possible explanations could include the lower experience with radiation sensitisers and the presumed gentler toxicity profile of cetuximab compared to cisplatin-based toxicity and sequelae, including renal dysfunction and hearing loss. Robust evidence for HNC management in elderly patients is still lacking, but several considerations can be made.

Firstly, both expertise and multidisciplinarity should be emphasised. It is reported that MU meetings change the diagnostic and/or therapeutic approach up to $60 \%$ of the cases, due to staging refinement and more frequent use of thera- peutic plan escalation ${ }^{7}$; according to the survey results the majority of RODs (85\%) discussed HNC cases in a MU. Secondly, few data exist on the presence of a geriatrician as an effective MU member; our survey recorded that only $6.9 \%$ of RODs regularly included a geriatrician in the MU team members. We have mainly ascribed this result to the lack of a standardised method to evaluate HNC elderly patients and the difficulty to integrate a complete geriatric evaluation in the daily clinical practice. Only a minority of RODs (10\%) performed a CGA in all elderly patients. Considering that many patients are susceptible to a curative treatment, an adequate geriatric evaluation at diagnosis is extremely relevant to guide therapeutic approach. The main risk is to under-treat or over-treat elderly patients due to their chronological age or their degree of frailty.

To date, the role of CGA is debated; the international society of geriatric oncology (SIOG) recommended its systematic use in the pre-treatment assessment of elderly people with cancer ${ }^{8}$, but it is still not validated in HNC management ${ }^{9}$. Actually, two randomised clinical trials ${ }^{10,11}$ have been designed to validate CGA in HNC patients, the preliminary results of one of these showed that CGA changed the planned treatment in $8 \%$ of patients ${ }^{12}$; nevertheless, no data has demonstrated that CGA ameliorates the results in $\mathrm{HN}$ cancer patients. It must also be considered that the main reported issue on systematic adoption of CGA is that take too much time to be performed routinely ${ }^{8}$, so often pre-screening evaluation using specific tools such as G8 or VES-13, was performed in order to identify those patients who require further geriatric assessment ${ }^{13}$. Both G8 and VES-13 are validated tools in HNC patients ${ }^{13}$ and several literature data clearly indicated that the $\mathrm{G} 8$ better correlates with geriatric assessment at baseline compared to the VES13 (sensitivity $85.7 \%$ versus $57.1 \%$, respectively) ${ }^{14}$. Therefore, the G8 should be considered the main screening tool to distinguish between fit from vulnerable HNC patients.

Lastly, the choice of the concomitant systemic therapy, the definition of target volumes and the fractionation schedules remain the major concerns. The meta-analysis of radiotherapy in carcinomas of head and neck (MARCH) collaborative group showed a decreasing effect of altered fractionated in older patients ${ }^{15}$. No firm conclusions can be stated mainly because the intrinsic questionable results generalisability in a meta-analysis and the lack of objective and reproducible criteria to evaluate elderly patient in the included studies.

In our analysis, despite the high percentage of curative treatments (89\%), a heterogeneous scenario was depicted, with different options chosen, including concurrent platinum-based chemoradiotherapy, RT plus cetuximab or definitive RT alone. Another key question concerns RT details, such as the distribution of radiation dose over time and target volume delineation. 
Radiation volume de-escalation could be an effective strategy to reduce toxicity and facilitate treatment compliance. High-quality RT and adequate patient selection should be promoted to guarantee reliable treatment outcome. In the literature, different experiences reduced RT volume avoiding elective nodal volume irradiation in elderly and frail patients with good rate of local control ${ }^{16-19}$. However, this is not the standard and it should be considered with caution in treatment with radical intent. Moreover, we underline that these data should be interpreted with caution for several issues such as, inhomogeneous study population, irradiation techniques or incomplete follow up ${ }^{16-19}$.

This survey had several limitations. First of all, the data do not represent the collection of individual patient data from a database but the answers from a respondent per each centre with inevitable introduction of bias due to uncertainty in data collection. The main inhomogeneities highlight in this survey correspond to points in which literature data does not reveal a clear standard of care. Second, we underline that only about a third of Italian RODs answered the survey (68 of 196 centres). However, considering that one of the missions of the AIRO is to promote research, it is our hope that the obtained data will be a strong incentive and form the basis for the AIRO Head and Neck working group to design a prospective clinical trial especially to identify optimal target volumes and clarify if, a subgroup of elderly patients, might benefit from combined treatment.

\section{Conclusions}

This survey documented a significant heterogeneity in the management of elderly patients with HNC. Adequate patient evaluation is mandatory and significant expertise is required to propose a patient-centred treatment. Prospective studies are needed for this setting of patients.

\section{Acknowledgements}

The content of the paper has been approved by the Scientific Committee of Italian Association of Radiotherapy and Clinical Oncology (AIRO).

\section{References}

1 Vermorken JB, Specenier P. Optimal treatment for recurrent/metastatic head and neck cancer. Ann Oncol 2010;21(Suppl 7):vii252-61. https://doi.org/10.1093/annonc/mdq453

2 Coca-Pelaz A, Halmos GB, Strojan P, et al. The role of age in treatmentrelated adverse events in patients with head and neck cancer: a systematic review. Head Neck 2019;41:2410-29. https://doi.org/10.1002/hed.25696

3 Pignon JP, le Maître A, Maillard E, et al. Meta-analysis of chemotherapy in head and neck cancer (MACH-NC): an update on 93 randomised trials and 17,346 patients. Radiother Oncol 2009;92:4-14. https://doi.org/10.1016/j.radonc.2009.04.014
4 Bonner JA, Harari PM, Giralt J, et al. Radiotherapy plus cetuximab for locoregionally advanced head and neck cancer: 5-year survival data from a phase 3 randomised trial, and relation between cetuximab-induced rash and survival. Lancet Oncol 2010;11:21-8. https:// doi.org/10.1016/S1470-2045(09)70311-0

5 National Comprehensive Cancer Network (NCCN). Guidelines Head and Neck Cancers, Version 1.2019. available at http://www.nccn.org

6 Hartigan JA, Wong MA. Algorithm AS. 136: a K-Means clustering algorithm. J R Stat Soc Ser C (Appl Stat) 1979;28:100-8.

7 Bossi P, Alfieri S. The benefit of a multidisciplinary approach to the patient treated with (chemo) radiation for head and neck cancer. Curr Treat Options Oncol 2016;17:53. https://doi.org/10.1007/s11864-016-0431-3

8 Decoster L, Van Puyvelde K, Mohile S, et al. Screening tools for multidimensional health problems warranting a geriatric assessment in older cancer patients: an update on SIOG recommendations. Ann Oncol 2015;26:288-300. https://doi.org/10.1093/annonc/mdu210

9 Maggiore R, Zumsteg ZS, BrintzenhofeSzoc K, et al.; CARG-HNC Study Group. The older adult with locoregionally advanced head and neck squamous cell carcinoma: knowledge gaps and future direction in assessment and treatment. Int J Radiat Oncol Biol Phys 2017;98:868-83. https:// doi.org/10.1016/j.ijrobp.2017.02.022.

10 Brugel L, Laurent M, Caillet P, et al. Impact of comprehensive geriatric assessment on survival, function, and nutritional status in elderly patients with head and neck cancer: protocol for a multicentre randomised controlled trial (EGeSOR). BMC Cancer 2014;14:427. https://doi.org/10.1186/1471-2407-14-427

11 ClinicalTrials.gov,https://clinicaltrials.gov/ct2/show/NCT03614936? term=NCT03614936\&rank=1. Accessed 04 October 2019.

12 Mertens C, Le Caer H, Ortholan C, et al. The ELAN-ONCOVAL (ELderly heAd and Neck cancer-Oncology eValuation) study: evaluation of the feasibility of a suited geriatric assessment for use by oncologists to classify patients as fit or unfit. Ann Oncol 2017;28(suppl. 5):v372-v94. https://doi.org/10.1093/annonc/mdx374

13 Soubeyran P, Bellera C, Goyard J, et al. Screening for vulnerability in older cancer patients: the ONCODAGE Prospective Multicenter Cohort Study. PLoS One 2014;9:e115060. https://doi.org/10.1371/ journal.pone.0115060

14 Pottel L, Boterberg T, Pottel H, et al. Determination of an adequate screening tool for identification of vulnerable elderly head and neck cancer patients treated with radio(chemo) therapy. J Geriatr Oncol 2012;3:24-32. https://doi.org/10.1016/j.jgo.2011.11.006

15 Bourhis J, Overgaard J, Audry H, et al.; Meta-Analysis of Radiotherapy in Carcinomas of Head and neck (MARCH) Collaborative Group. Hyperfractionated or accelerated radiotherapy in head and neck cancer: a meta-analysis. Lancet 2006;368:843-54. https://doi. org/10.1016/SO140-6736(06)69121-6

16 Bernier J, Bataini JP. Regional outcome in oropharyngeal and pharyngolaryngeal cancer treated with high dose per fraction radiotherapy. Analysis of neck disease response in 1646 cases. Radiother Oncol 1986;6:87-103. https://doi.org/10.1016/s0167-8140(86)80015-9

17 Boysen M, Lovdal O, Soberg R, et al. Elective radiotherapy of the neck in patients with squamous cell carcinoma of the head and neck. ORL J Otorhinolaryngol Relat Spec 1992;54:103-7. https://doi. org/10.1159/000276274

18 Mendenhall WM, Million RR, Cassisi NJ. Elective neck irradiation in squamous-cell carcinoma of the head and neck. Head Neck Surg 1980;3:15-20. https://doi.org/10.1002/hed.2890030105

19 Van den Bosch S, Dijkema T, Verhoef LC, et al. Patterns of recurrence in electively irradiated lymph node regions after definitive accelerated intensity modulated radiation therapy for head and neck squamous cell carcinoma. Int J Radiat Oncol Biol Phys 2016;94:766-74. https:// doi.org/10.1016/j.ijrobp.2015.12.002 